\title{
TORSIONAL, COMPRESSION AND SHEAR STIFFNESS OF THIN-LAYER RUBBER- METAL SPHERICAL JOINT-HINGE
}

\author{
Svetlana Polukoshko ${ }^{1}$, Andris Martinovs ${ }^{2}$, Vladimirs Gonca ${ }^{3}$ \\ ${ }^{1}$ Ventspils University College, Latvia; ${ }^{2}$ Rezekne Academy of Technologies, Latvia; \\ ${ }^{3}$ Riga Technical University, Latvia \\ pol.svet@inbox.lv, andris.martinovs@ru.lv, vladimirs.gonca@rtu.lv
}

\begin{abstract}
In this paper laminated elastomeric bearings (composite of thin elastomer and metal layers) are considered. This type of bearings or joint-hinge has many advantages because of ease of maintenance; ability to work in a very aggressive environment, low cost and vibration damping capability. The geometric shape of such bearing may be planar, cylindrical, conical, spherical and other, given work deals with spherical thin-layered rubber-metal bearings. Operating of such device depends on many factors that must be considered on the design stage: parameters of the elements must be selected properly. The most important parameter is stiffness dependence between imposed force and received deformation. In this work torsional, compression and shear stiffness of laminated bearings was defined for the testing specimens by experiments and torsional stiffness was received analytically. Both methods show good enough coincidence.
\end{abstract}

Keywords: elastomers, rubber bearing, laminated rubber hinge, stiffness, torsion, shear, compression.

\section{Introduction}

Rubber and rubber-like materials (elastomers) exhibit specific properties: high elasticity, resistance to aggressive environmental factors, good dynamic properties, low volume compressibility, linear relationship between stress and strain up to strain of 15-20\%. Elastomeric materials offer many engineering advantages and are widely used in machine building, shipbuilding, civil engineering, aviation and aerospace as compensation devices, vibration dampers, shock absorbers [1-6].

Reinforced elastomers, or laminated elastomeric structures, consist of a large number of alternating thin layers of elastomeric and reinforcing layers of other much more rigid material, usually metal. The connection of elastomeric and reinforcing layers is usually fulfilled by means of vulcanization or gluing. Such structures are successfully replacing the traditional technical systems because of their ability to endure high stress (>200 MPa) and low ratio of shear/bulk compression moduli $[2 ; 7]$. The evident advantages of laminated elastomeric structures are: ease of maintenance; impossibility of jamming in case of breakage; no necessity for lubrication, ability to work in a very dirty, dusty, abrasive environment; vibration and noise reduction; improving the dynamics of machines, which provide the properties of rubber and lack of clearances, as well as compensation of various skew distortions and inaccuracies in the joint connection; smaller size, weight and cost. Packages of thin-layered rubber-metal elements (further TRME) are successfully used as bearings, joints, dampers, compensating devices, shock-absorbers etc. In practice the TRME packages of different geometric shapes are used: planar, cylindrical, conical, spherical and others; the number of layers may be different, at least three. The planar elements of the TRME began to be studied from the 1960s and now they are investigated good enough. The spherical TRME constructions are less studied, but the possibilities of their using are very wide [8;9]. The examples of packages of spherical TRME are shown in Fig. 1.

a)

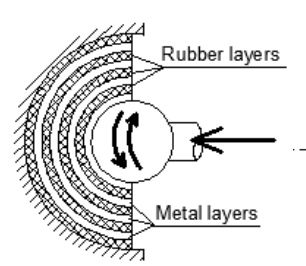

b)

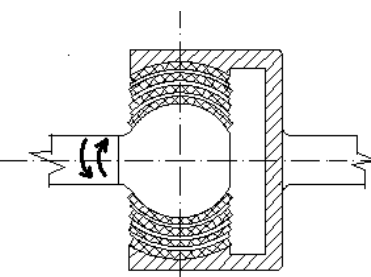

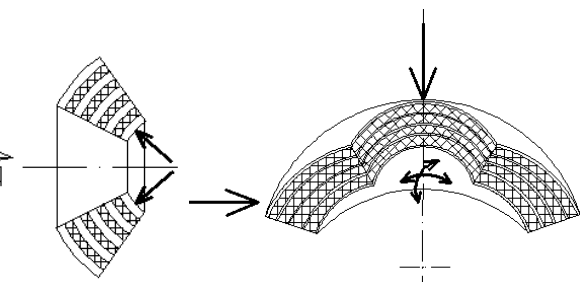

d)

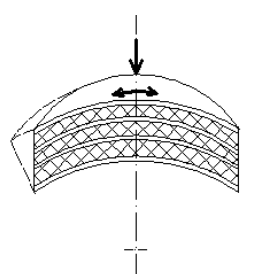

Fig. 1. Examples of packages of spherical form TRME: $a$-spherical bearing; $b$-spherical nozzle; c) - hemispherical bearing; d) - spherical pad

In the present paper the compression, shear and torsion stiffness characteristics of spherical type multi-layered rubber - metal package under static loading are considered. Stiffness (dependence 
between the imposed force and received deformation) is the most important parameter of such devices. Torsion, shear and compressive stiffness for special samples were defined by means of experiments; torsional stiffness was obtained also analytically.

\section{Materials and methods}

The testing of spherical elements was carried out at the Moscow Scientific Research Institute VNIINMASH on the universal precision testing machines TT-DM and TT-KM of "Instron" Company with a maximum force of $250 \mathrm{kN}$. In order to perform the tests, six types of samples were prepared; the data of the specimens are presented in Table 1. In the manufacture of all spherical specimens, rubber was used of the 8871 grade and sheet steel of St.3 grade. The construction of testing the spherical TRME package is shown in Fig.1a, each of its rubber and metal layers is a segment of a sphere, where each layer has the same center point. That makes it possible for rubber layers of the package to be shifted sideways in any direction, tangential to their common center point, as well as to rotate angularly around the longitudinal axis.

Testing elements dimensions

Table 1

\begin{tabular}{|c|c|c|c|c|c|c|c|c|}
\hline $\begin{array}{c}\text { Number } \\
\text { of } \\
\text { elements } \\
\text { No }\end{array}$ & $\begin{array}{c}\text { Diameter, } \\
\mathbf{m m}\end{array}$ & $\begin{array}{c}\text { Radius } \\
\text { of } \\
\text { sphere } \\
\boldsymbol{D}\end{array}$ & $\begin{array}{c}\text { inner } \\
\boldsymbol{d}\end{array}$ & $\begin{array}{c}\text { Thickness } \\
\text { of one } \\
\text { rubber } \\
\text { layer, mm }\end{array}$ & $\begin{array}{c}\text { Number } \\
\text { of } \\
\text { rubber } \\
\text { layers, } \boldsymbol{n} \\
\text { items }\end{array}$ & $\begin{array}{c}\text { Total } \\
\text { thickness } \\
\text { of rubber } \\
\text { layers, } \\
\text { mm }\end{array}$ & $\begin{array}{c}\text { Thickness } \\
\text { of one } \\
\text { metal } \\
\text { layer, } \\
\text { mm }\end{array}$ & $\begin{array}{c}\text { Number } \\
\text { of metal } \\
\text { layers, } \\
\text { items } \\
\boldsymbol{n}+\mathbf{1}\end{array}$ \\
\hline 1 & 101 & 50 & 80 & 0.70 & 3 & 2.10 & 0.6 & 4 \\
\hline 2 & 101 & 50 & 80 & 0.47 & 5 & 2.38 & 0.6 & 3 \\
\hline 3 & 101 & 50 & 80 & 0.55 & 5 & 2.79 & 0.6 & 6 \\
\hline 4 & 101 & 50 & 80 & 0.70 & 6 & 4.21 & 0.6 & 7 \\
\hline 5 & 101 & 50 & 80 & 0.42 & 10 & 4.19 & 0.6 & 11 \\
\hline 6 & 101 & 50 & 80 & 1.24 & 10 & 12.38 & 0.6 & 11 \\
\hline
\end{tabular}

\section{a) Compression stiffness definition}

For compression testing two packages 1 are compressed together between two parallel plates 4 and 5. The compression force is created by the movement of the traverse 6 downward. The lower plate is fixed to the force sensor 2 (Fig. 2b). The compression deformation of the TPMPE is measured by two sensors of displacement 3 . Special tensometric displacement sensors were used to exclude the influence of deformation of the loading system and to measure deformation directly between the plates that compress the sample.

a)

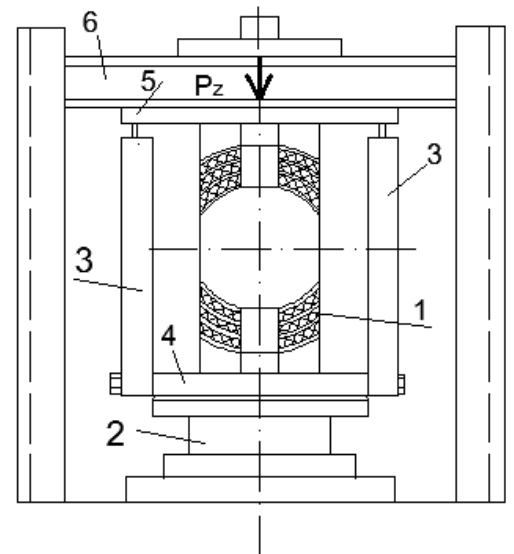

b)

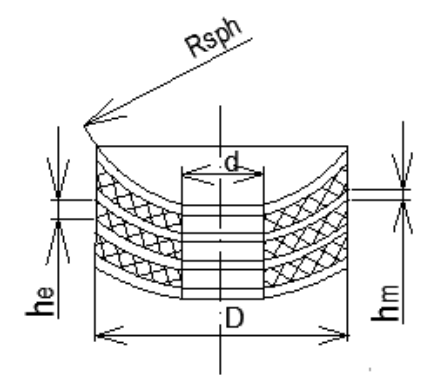

$h_{e}-$ elastomeric layer thickness,

$h_{m}$ - metal layer thickness,

$R_{\text {shp }}$ - ball-bearing radius.

Fig. 2. a) Construction of spherical TRME package; b) Compression test of spherical damper

The dependence of the compression stiffness $K_{z}$ of spherical TPME on the specific compression load, which is defined as the ratio of the compression force to the area of the projection of the base surface of the sample: 


$$
p_{z}==\frac{P_{z}}{A_{\text {red }}}, A_{\text {red }}=\frac{\pi}{4}\left(D^{2}-d^{2}\right) .
$$

The area $A_{\text {red }}$ for all spherical elements is equal to $60.5 \mathrm{~cm}^{2}$ and the stiffness at compression $K_{z}$ was determined in differential form by the formula:

$$
K_{z}=\frac{\Delta P_{z}}{A_{\text {red }} \Delta h}, \Delta P_{z}=P_{z n+1}-P_{z n}, \Delta h=h_{n+1}-h_{n},
$$

where $\Delta h-$ decrease of the total thickness of the rubber element under load $\Delta P_{z}$; $\Delta P_{z}$ - increment in the compression force.

\section{b) Torsional and shear stiffness definition}

The test facility is shown in Fig.3b; when testing spherical TPME under torsion, two samples are compressed together with the ball 2 between the spherical plates 3 and 4 . The precompression force $P_{\mathrm{z}}$ is created by movement of the traverse 5 downward and is measured by the force sensor 6 . The torsion of the TPME is ensured by rotating the pivot shaft 7 , rigidly fastened to the ball 2 , around the $z$ axis.

a)

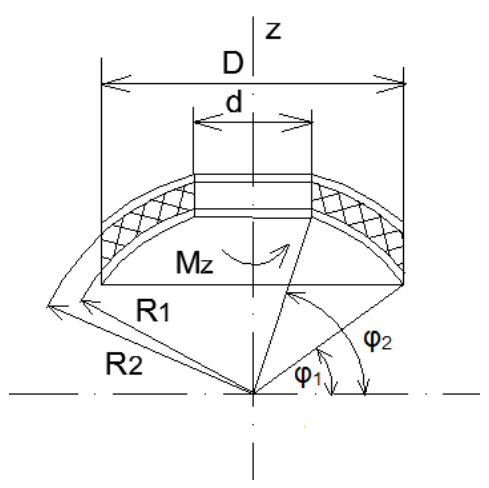

b)

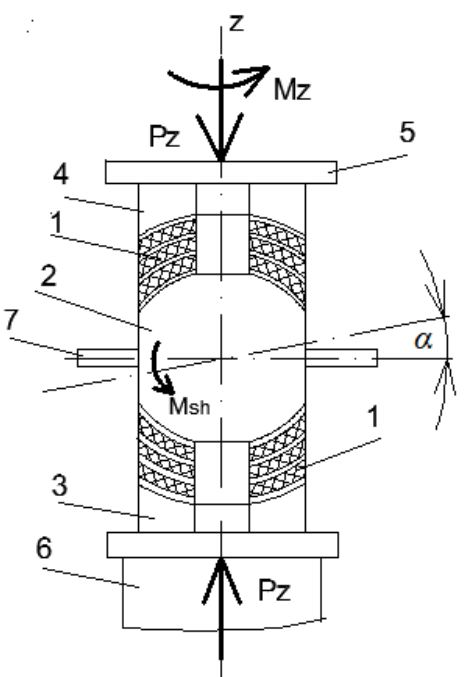

c)

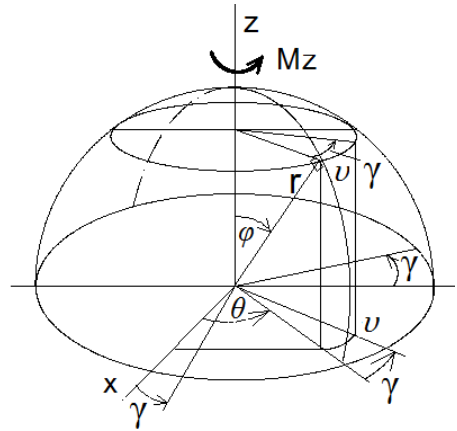

Fig. 3. a) Scheme of one spherical rubber element; b) scheme of testing of TRME package under torsion and shear; c) Spherical coordinate system

The torsional force $P_{t o r}$ is measured by a dynamometer. The stiffness of thin-layer elements with torsion $K_{\text {tor }}$ is determined by the formula:

$$
K_{t o r}=\frac{\Delta M_{t o r}}{\Delta \varphi}=\frac{\Delta P_{t o r} l}{\Delta \varphi},
$$

where $\Delta \varphi$ - increment of the angular deformation of the TPMPE under torsion with a corresponding increase of the torsional moment by $\Delta M_{\text {tor }}$;

$l$ - distance from the center of the sphere to the point of application of the force $P_{t o r}$.

The test procedure for the spherical TPME under shear differs from the test procedure for torsion by rotating of the pivot shaft 7 on the angle of shear $\alpha$ in the plane of the drawing. The stiffness of thin-layered elements under shear is also determined in the differential form:

$$
K_{s h}=\frac{\Delta M_{s h}}{\Delta \alpha}=\frac{\Delta P_{s h} l}{\Delta \alpha},
$$

where $\Delta \alpha$-increment of angular deformation under shear with corresponding increasing of the shear moment on $\Delta M_{s h}$;

$l$ - distance from the center of the sphere to the point of application of the shear force. 
Analytical expression for the torsial stiffness definition is derived below. One rubber layer of the TRME package is presented in Fig. 3a. For theoretical decision the spherical coordinate system was chosen (Fig. 3c) with coordinates $r, \varphi, \theta$ :

$$
R_{1} \leq r \leq R_{2},\left(0.5 \pi-\varphi_{2}\right) \leq \varphi \leq\left(0.5 \pi-\varphi_{1}\right), 0 \leq \theta \leq 2 \pi,
$$

where $R_{1}$ - internal radius of the rubber layer;

$R_{2}$ - exterior radius of the rubber layer;

$r$ - variable radius of sphere;

$\varphi$ - variable angular coordinate,

In the spherical TPME under torsion only one displacement $v$ will be in the direction of increasing of the polar angle $\theta$. The function $v$ is found by integrating of the differential equation of equilibrium:

$$
\frac{\partial^{2}(r v)}{\partial r^{2}}+\frac{1}{r} \frac{\partial}{\partial \varphi}\left[\frac{1}{\sin \varphi} \frac{\partial}{\partial \varphi}(v \sin \varphi)\right]=0 \text {. }
$$

The displacement $v$ for the one rubber-metal element is sought in the form: $v=\gamma \eta(r) \sin \varphi$, where $\gamma$ is the angle of torque. Then the differential equation for the function $\eta(r)$ is written as :

$$
r \frac{\partial^{2} \eta(r)}{\partial r^{2}}+2 \frac{\partial \eta(r)}{\partial r}-2 \frac{\eta(r)}{r}=0
$$

If the upper metal layer is immovable, the boundary conditions for the function $v$ and, consequently, for the function $\eta(r)$ have the forms:

$$
v\left(r=R_{2}\right)=0, v\left(r=R_{1}\right)=R_{1} \gamma \sin \varphi, \eta\left(r=R_{2}\right)=0, \eta\left(r=R_{1}\right)=R_{1} .
$$

The solution of the equation (6) under boundary conditions (7) has the form:

$$
\begin{gathered}
\eta(r)=C_{1} r+C_{2} \frac{1}{r^{2}}, C_{1}=-\frac{R_{1}^{3}}{R_{2}^{3}-R_{1}^{3}}, C_{2}=\frac{R_{1}^{3} R_{2}^{3}}{R_{2}^{3}-R_{1}^{3}} ; \text { or: } C_{1}=-\frac{a}{R_{2}^{3}}, C_{2}=a, \\
\quad \text { where } a=\frac{R_{1}^{3} R_{2}^{3}}{R_{2}^{3}-R_{1}^{3}} .
\end{gathered}
$$

In this case only tangential stress is acting:

$$
\tau_{\theta r}=G\left(\frac{\partial v(r)}{\partial r}-\frac{v(r)}{r}\right)=G \gamma\left(\frac{\partial \eta(r)}{\partial r}-\frac{\eta(r)}{r}\right) \sin \varphi=-3 G \gamma \frac{R_{2}^{3} R_{1}^{3}}{R_{2}^{3}-R_{1}^{3}} \frac{1}{r^{3}} \sin \varphi=-3 G \gamma \frac{\alpha}{r^{3}} \sin \varphi \text {. }
$$

Then the relationship between the torsion moment $M_{z}$ and the angle of torsion $\gamma$ is found from the equilibrium condition of the movable plate $\left(r=R_{1}\right)$ :

$$
M_{z}=-\int_{0}^{2 \pi} \int_{0.5 \pi-\varphi_{2}}^{0.5 \pi-\varphi_{1}}\left(\tau_{\theta r \mid r=R_{1}}\right) R_{1}^{3} \sin \varphi d \varphi d \theta=3 \pi G \gamma a\left\{\left(\varphi_{2}-\varphi_{1}\right)-0.5\left[\sin \left(2 \varphi_{1}\right)-\sin \left(2 \varphi_{2}\right)\right]\right\} .
$$

Torsional stiffness of one layer is $K_{t o r}=\frac{M_{z}}{\gamma}$, for the package with $n$ layers $K_{t o r}=\frac{M_{z}}{n \gamma}$.

Under the condition of $\varphi_{2}=71^{\circ} 47^{\prime}$ and $\varphi_{1}=50^{\circ} 51^{\prime}$,

$$
M_{z}=1.667 \pi G \gamma a, K_{z}=1.667 \pi G a, \mathrm{Nm} \cdot \mathrm{rad}^{-1} .
$$

\section{Results and discussion}

The results of the executed experiments are presented below in a graphic form. The dependence of the compression stiffness $K_{z}$ on the specific compression load $p_{z}$ is shown in Fig. 4a, the dependence of axial displacement $\Delta_{z}$ on $p_{z}$ - in Fig. $4 \mathrm{~b}$. Specimens with higher rubber layers have 
lower stiffness. Stiffness $K_{z}$ increases with decreasing of thickness of the rubber layer and has a hardening non-linear characteristic.

Experimental and theoretical dependences of torsion stiffness on the torque moment $M_{z}$ are given in Fig. 5, experimental data of $K_{\text {tori }}$ are depicted as solid lines and theoretical data $K_{\text {torit }}$-as dot lines. Shear module $G$ for rubber of grade 8871 is $0.45 \mathrm{MPa}$, but for calculation stiffness in accordance with (10), taken into account the adhesive layer influence, we assumed $G$ equal to $0.62 \mathrm{MPa}$ [10]. The theoretical torsion stiffness does not depend on the applied torsion moment, the experimental values mainly coincide with the calculated theoretical values. The best coincidence of the theoretical and experimental data is shown by the specimen No 6 with the largest height of one rubber layer and the largest total height. The stiffness of the TPME in torsion has a soft characteristic (i.e., the stiffness decreases with increasing the load) and, as shown by the experiment, it does not depend on the force of pre-compression.

a)

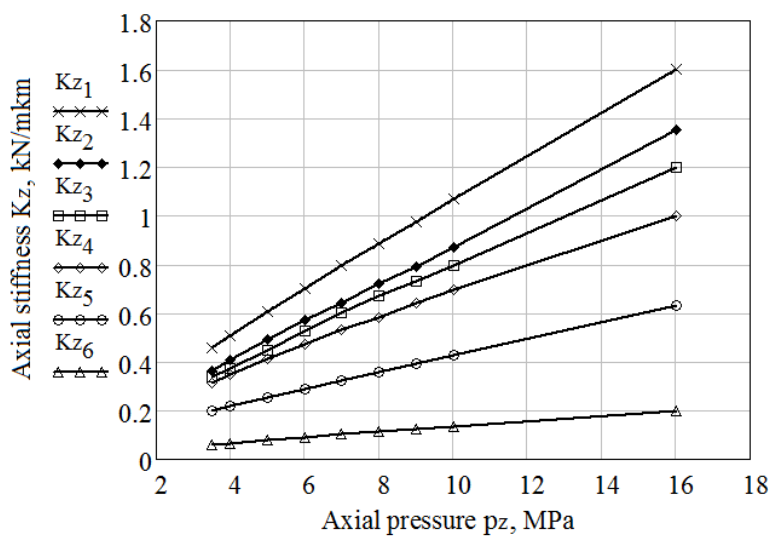

b)

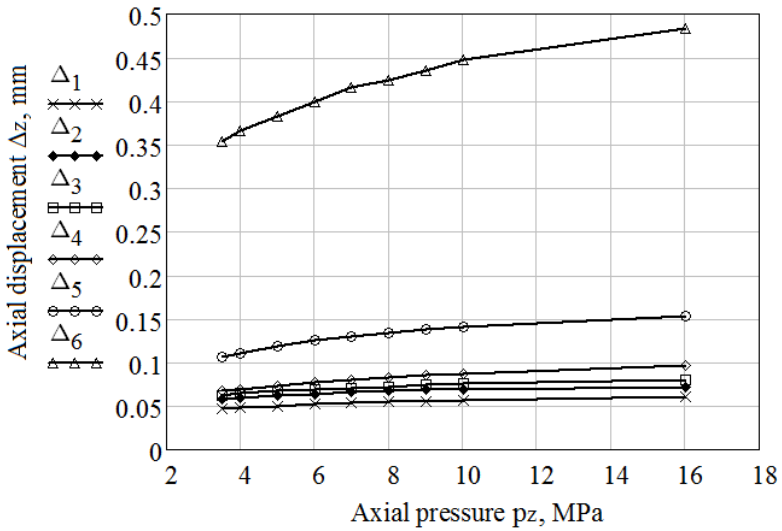

Fig. 4. a) Dependence of axial stiffness of spherical TRME on axial pressure; b) dependence of axial displacement on axial pressure

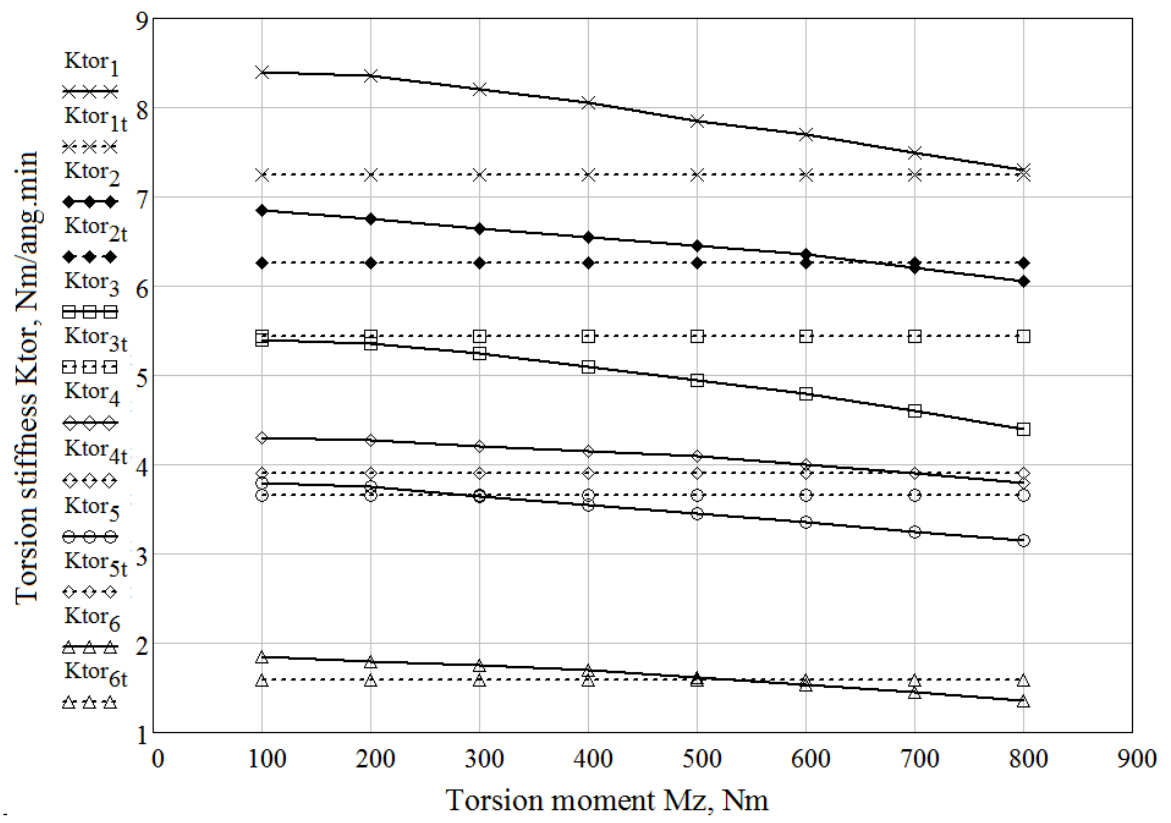

Fig. 5. Dependence of torsional stiffness of spherical TRME on torsional moment

The plots of dependence of shear stiffness on the shear moment are presented in Fig. 6. The dependencies of $K_{s h}$ on $M_{s h}$ also have a soft characteristic and do not depend on the force of precompression. The shear stiffness is much more than the torsion stiffness. 
When the stiffness properties of a spherical laminated bearing are known, the corresponding TRME devices may be correctly designed.

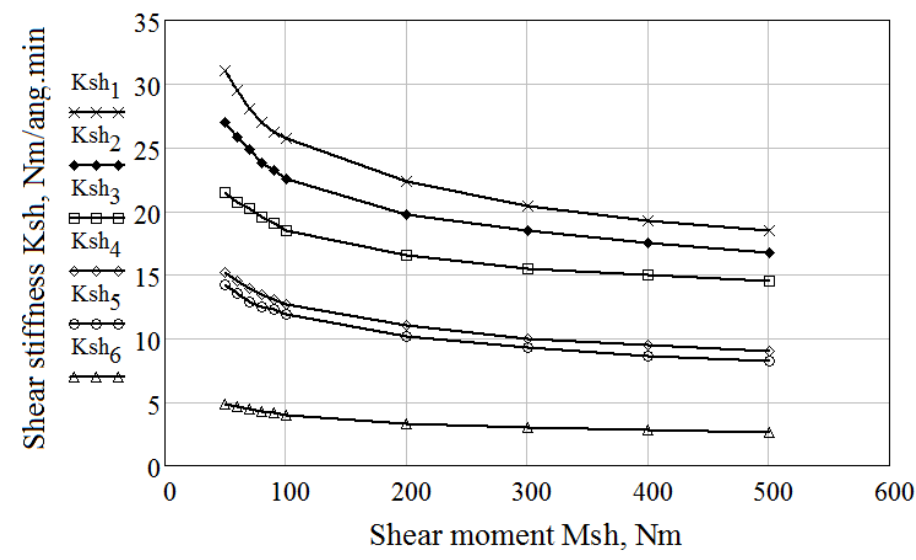

Fig. 6. Dependence of shear stiffness of spherical TRME on shear moment

\section{Conclusions}

1. In the paper the compressive, torsional and shear stiffness of the laminated rubber bearing of spherical shape are defined for the six types of specimen by experiments; plots of dependence of the respective stiffness on the applied force are drawn in Mathcad - 15 program. Stiffness $K_{z}, K_{t o r}$ and $K_{s h}$ increases with decreasing of the thickness of one rubber layer; for equal thickness of one layer stiffness decreases with the number of layers increasing.

2. Compression stiffness $K_{z}$ has a hardening non-linear characteristic, i.e. stiffness increases with the axial pressure $p_{z}$ increasing.

3. Torsion stiffness $K_{t o r}$ has a soft characteristic (i.e., stiffness decreases with load increasing) and, as it was shown by the experiment, it does not depend on the pre-compression force.

4. Shear stiffness also has a soft characteristic and does not depend on the pre-compression force. The shear stiffness of the spherical bearing is much more than the torsion stiffness.

5. Analytical expression is derived for torsion stiffness definition and the experimental data are in good agreement with the theory. The future stage of this work is to elaborate analytical equations for shear and compression stiffness.

\section{References}

1. Gent A.N. Engineering with Rubber: How to Design Rubber Components. Munich: Carl Hanser Verlag, 2011. $428 \mathrm{p}$.

2. Kelly, J.M. and Konstantinidas, D.A. Mechanics of Rubber Bearings for Seismic and Vibration Isolation. UK: John Wiley \& Sons, 2011. 222 p.

3. Gent A.N., Meinecke E.A.Compression, bending and shear of bonded rubber blocks. Polymer Engineering and Science, Vol. 10 (2), 1970, pp. 48-53.

4. Banks H.T., Pinter G.A.,Yeoh O.H. Analysis of bonded elastic blocks. Mathematical and Computer Modelling, Volume 36, Issues 7-8, November 2002, pp. 875-888.

5. Ляпунов В. Т., Лавендел Э. Э., Шляпочников С. А. Резиновые виброизоляторы (Rubber vibration isolators Habdbook.). Leningrad: Sudostrojenie, 1988. 216 p. (In Russian).

6. Гусятинская Н.С. Применение тонкослойных резинометаллических элементов (ТРМЭ) в станках и других машинах (Application of Thin Layer Rubber-Metal Elements in MachineTools and Other Engines). Moscow: Mashinostroenie, 1978. 83p (In Russian).

7. Фролов Н.Н., Молдаванов С.Ю., Лозовой С.Б. Механика тонкослойных резинометаллических элементов: монография (Mechanics of Thin-layer Rubber-Metal Elements: monograph). Krasnodar: Publishing House "Jug”, 2011. 218 p. (In Russian).

8. William L. Hinks, Randolph Research Co. (RRC). Laminated-rubber bearings: from helicopters to the deep sea new potentials for undersea controls. Presented at UUST11, Portsmouth, NH, Aug. 20-24, 2011. Available at: 
http://randolphresearch.com/Laminated \%20Bearings \%20from \%20Helicopters \%20to \%20the \% 20Deep \%20Sea_6_Talk_5.doc.htm

9. William L. Hinks, Randolph Research Co. (RRC). Laminated-rubber bearings: heavy duty composites for aerospace and undersea. Presentation at the Spring 2013 183rd Technical Meeting of the Rubber Division of the American Chemical Society. Available at:

http://randolphresearch.com/LAMINATED \%20Rubber \%20Bearings \%20Rubber \%20Div \%20p aper2_trim.htm

10. Gonca V., Polukoshko S. and Hilkevica G. Adhesive Layer Influence on Compressive and Tension Stiffness of Thin-Layer Rubber-Metal Elements. Proceeding of VETOMAC X 2014, Manchester, UK, September 9-11, 2014. In Marko Ceccarelli (ed.), Springer, Series: Mechanism and Machine Science, Volume 23, 2014, pp. 697-707. 